\title{
Cognitive deficits in multiple sclerosis
}

\section{A systematic review}

\author{
Maria Lúcia Brito Ferreira’
}

\begin{abstract}
Objective: To present the results of prospective and retrospective studies on multiple sclerosis patients cognitive dysfunctions, as well as to discuss the batteries of neuropsychological tests used in these investigations. Method: A systematic review was performed involving 40 studies published from 1997 to 2009, in PubMed, Scopus, Ovid, ISI Web of Knowledge, Scientific Electronic Library on line (Scielo) and Latin-American and Caribbean Center of Health Sciences Informations database. Clear description of multiple sclerosis patients cognitive deficits evaluation, study design, sample size; inclusion-exclusion and discontinuation criteria; instruments for neuropsychological evaluation, diagnostic methods, evaluated functions and detailed statistical analysis had been the inclusion criteria. Results: There is consensus on cognitive impairment of multiple sclerosis patients, especially on memory, speed processing, executive function, attention and concentration domains. One has identified use of 23 batteries and 74 neuropsychological tests, despite the recommendation of Consortium of Multiple Sclerosis Centers to the application of MACFIMS battery. Considerations: The absence of the uniformization for multiple sclerosis patients cognitive evaluation battery has precluded to achieve evidences to recommend its incorporation on diagnostic routine. Nevertheless this tendency is already outlined.
\end{abstract}

Key words: multiple sclerosis, cognitive dysfunctions, neuropsychological batteries.

\section{Déficits cognitivos na esclerose múltipla: uma revisão sistemática}

\section{RESUMO}

Objetivo: Apresentar os resultados de estudos prospectivos e retrospectivos sobre disfunções cognitivas em pacientes com esclerose múltipla, assim como discutir as baterias de testes neuropsicológicos empregadas em tais investigações. Método: Uma revisão sistemática foi realizada envolvendo 40 estudos publicados no período de 1997 a 2009, nas bases de dados PubMed, Scopus, Ovid, ISI Web of Knowledge, Scientific Electronic Library on line (Scielo) e Centro Latino-Americano e do Caribe de Informação em Ciências da Saúde. Descrição clara de: avaliação de déficits cognitivos em pacientes com esclerose múltipla, desenho do estudo, tamanho amostral, critérios de inclusão, exclusão e descontinuação, instrumentos de avaliação neuropsicológica, métodos diagnósticos, funções avaliadas e detalhamento da análise estatística foram critérios de inclusão. Resultados: Há consenso quanto ao comprometimento cognitivo de pacientes com esclerose múltipla, especialmente nos domínios de memória, velocidade de processamento, função executiva, atenção e concentração. Identificou-se o emprego de 23 baterias e 74 testes neuropsicológicos, apesar da recomendação do Consórcio de Centros de esclerose múltipla para emprego da bateria MACFIMS. Considerações: $A$ falta de uniformização da bateria de avaliação cognitiva desses pacientes está impedindo que se obtenham evidências para recomendar sua incorporação como rotina diagnóstica. Mesmo assim essa tendência já se delineia.

Palavras-chave: esclerose múltipla, disfunções cognitivas, baterias neuropsicológicas. 
Multiple sclerosis (MS) is a progressive disease, characterized by the presence of plaques in brain and spinal $\operatorname{cord}^{1}$ and to be one of the most frequent causes of central nervous system (CNS) disease of young adults ${ }^{2}$. These lesions have a demyelinating character associated with axonal loss ${ }^{1,2}$. In early phase of the disease, inflammatory process seems to predominate, but, lately in disease evolution, there is a predominance of degenerative process ${ }^{2}$.

Despite the exact MS etiology still unknown, it has been admitted immunological and genetic hypothesis and the influence of environment factors. Due to the diffuse character of plaque formation, in MS there is a great diversity of motor, sphincter, sensitive, visual, coordination and cognitive symptoms and signs. The last one only recently has been focus of researches ${ }^{1,3,4}$.

Thirty years ago, one admitted that cognitive deficits impaired nearly $3 \%$ of MS patients and these disturbances traditionally were described as having heterogeneous nature and predominating in late stages ${ }^{5}$. Although recent studies indicate a prevalence varying from $43 \%$ to $72 \%$, affecting patients in early as well as in late stages ${ }^{1}$, and demonstrate that neuropsychological impairment seems to be associated to clinical evolution and severity. In remittent/recurrent (RR) clinical form, there are less impairment than in progressive forms ${ }^{6}$.

Many cognitive aspects are impaired in MS, including attention, learning, visuospatial abilities, memory, information processing speed and executive functions, and might be an important cause of disability ${ }^{4}$.

The evaluation of cognitive impairment in MS patients became theme of interest for health professionals since this disease affects young persons and the cognitive deficits not only reflect on emotional, social, and working activities, but also on sexuality and routine activities, what implies on loss of quality of life, even when physical disability is minimal ${ }^{7}$. For these reasons, an accurate evaluation of cognitive impairment, applying neuropsychological methods, may be a helpful instrument to the comprehension of the disease neurophysiologic aspects, as well as it can awake the sensibility for the problems with which the patients have to face ${ }^{2,8}$.

Data related to these impairments are still controversial according to severity, cognitive aspects, and its relation to CNS lesions diagnosed by image. The objective of this systematic review is to present the results of prospective and retrospective studies on cognitive alterations in MS patients, as well as to discuss the batteries of neuropsychological tests applied in these investigations.

\section{METHOD}

Within PubMed, Scopus, Ovid, ISI Web of Knowledge, Scientific Electronic Library on line (Scielo), and LatinAmerican and Caribbean Centers of Health Sciences In- formation database, one has searched for articles using as descriptors: multiple sclerosis, cognitive deficits, magnetic resonance image (MRI), MS clinical forms, expanded disability status scale (EDSS), neuropsychological test, neuropsychological battery, published from 1997 to 2009, in which there were clearly defined study design, sample size, inclusion-exclusion and discontinuation criteria, neuropsychological evaluation instruments, diagnostic methods, evaluated functions and detailed statistical analysis.

Fifty six articles were identified and submitted to a committee composed by the author and a health professional to independently criticize technical content, trying to find out consensus in a second phase. Forty articles were selected, among which 17 were clinical studies (13 case-control type ${ }^{5,6,8-18}$ and four cohorts ${ }^{15,19-21}$ ). Eight articles analyzes the association between cognitive deficits and MRI findings ${ }^{22-29}$. Two studies focused confounding factors for the analysis of neuropsychological tests results in MS patients $^{1,2}$. Seven other articles investigate the composition of batteries and their application techniques ${ }^{4,7,30-34}$, while six articles were no systematic reviews on this theme ${ }^{35-40}$. The characterization of these 40 articles is detailed in Table.

Sixteen articles were excluded; five due to methodological failure, one because the evaluation has been restricted to MS relapse phase, another that restricted the analysis to childhood and adolescence; three that emphasized fatigue and humor and three other to rehabilitation and treatment. One study included patients with depression and another analyzed visual evoked potentials variations. One study aimed to standardize the analysis of Minimal Assessment of Cognitive Function in Multiple Sclerosis (MACFIMS).

This article is divided into three sections. On the first, we present and discuss the findings of each one of 12 neuropsychological functions investigated, including memory, attention, concentration, information processing, executive function, abstract reasoning, visuoconstructive ability, visuospatial ability, processing speed, learning, orientation and verbal fluency. On second section, we remark technical aspects related to the batteries used in the selected studies and on third section, we present evidences and recommendations based on these studies.

\section{Development}

\section{Results related to cognitive functions - Memory, processing speed and executive functions}

Executive functions concern to cognitive abilities necessary to behavior directed to objectives and to the adaptation to environment demands and changes. These functions include the ability for planning, anticipate results and directing resources adequated to objectives. Deficits in executive functions in MS patients occur less frequently than memory or processing speed disability ${ }^{1}$. 
Table. Characteristics of 40 articles included in this review.

\begin{tabular}{|c|c|c|c|c|c|c|c|c|c|}
\hline \multirow[b]{2}{*}{ Author } & \multirow[b]{2}{*}{ Year } & \multirow[b]{2}{*}{ Study type } & \multicolumn{2}{|c|}{ Sample } & \multirow[b]{2}{*}{ EDSS } & \multicolumn{4}{|c|}{ Clinical forms } \\
\hline & & & Case & Control & & RR & SP & PP & $\mathrm{CIS}$ \\
\hline Mathiesen et al. ${ }^{22}$ & 2006 & Case-control with MRI & 20 & & & 20 & - & - & - \\
\hline Randolph et al. ${ }^{24}$ & 2005 & Case-control with MRI & 20 & 17 & $2.0 \pm 1.4$ & 20 & - & - & - \\
\hline Foong et al. ${ }^{25}$ & 1997 & Case-control with MRI & $42^{1}$ & 40 & $6.26 \pm 1.45$ & 11 & 28 & 3 & - \\
\hline Inglese et al. ${ }^{26}$ & 2008 & Case-control with MRI & 32 & 11 & $4.0(3-7)$ & 18 & - & 14 & - \\
\hline Mesaros et al. ${ }^{27}$ & 2009 & Case-control with MRI & 54 & 21 & $\leq 3.0$ & 54 & - & - & - \\
\hline Nebel et al. ${ }^{29}$ & 2007 & Case-control with MRI & 12 & 6 & $2.0-5.0$ & 12 & - & - & - \\
\hline Morgen et al..$^{28}$ & 2006 & Case-control with MRI & 19 & 19 & $<4.0$ & 19 & - & - & - \\
\hline Penner et al..$^{23}$ & 2006 & Series of cases with MRI & 15 & - & - & - & - & - & - \\
\hline Barco et al. ${ }^{6}$ & 2008 & Case-control & 51 & 51 & $<3.0$ & 51 & - & - & - \\
\hline Diamond et al. ${ }^{9}$ & 2008 & Case-control & 39 & 20 & $1.5-6.0$ & 23 & 10 & 6 & - \\
\hline Schulz et al. ${ }^{5}$ & 2006 & Case-control & 21 & 22 & $2.0(1.0-7.0)$ & 16 & 5 & - & \\
\hline Scherer et al. ${ }^{10}$ & 2007 & Case-control & 108 & 33 & $\leq 7.0$ & 80 & 24 & 4 & - \\
\hline Huijbregts et al. ${ }^{11}$ & 2006 & Case-control & 234 & 67 & $2.4 \pm 1.1-5.8 \pm 1.6$ & 108 & 71 & 55 & - \\
\hline Griffiths et al. ${ }^{12}$ & 2005 & Case-control & 83 & 80 & $3.1 \pm 2.2$ & 60 & 23 & - & \\
\hline Andrade et al. ${ }^{13}$ & 1999 & Case-control & 25 & 24 & $0-6.0$ & 25 & - & - & - \\
\hline Arango-Lasprilla et al..$^{18}$ & 2007 & Case-control & 80 & 40 & - & 55 & 17 & 8 & - \\
\hline Potagas et al. ${ }^{17}$ & 2008 & Case-control & 160 & 43 & $1.5-5.6$ & 75 & 29 & 23 & 33 \\
\hline Dineen et al. ${ }^{16}$ & 2009 & Case-control & 37 & 27 & $1.5-6.5$ & 35 & 2 & - & - \\
\hline Benedict et al. ${ }^{41}$ & 2006 & Case-control & 291 & 56 & $3.0 \pm 1.8$ & 200 & 78 & 13 & - \\
\hline Balsimelli et al. ${ }^{14}$ & 2007 & Case-control & 115 & 40 & $2.21 \pm 1.49$ & 115 & - & - & - \\
\hline Amato et al. ${ }^{8}$ & 2006 & Case-control & 163 & 111 & $<3.0$ & 163 & - & - & - \\
\hline Huijbregts et al. ${ }^{11}$ & 2006 & Cohort & 55 & 33 & $5.0-5.9$ & - & 30 & 25 & - \\
\hline Jønsson et al. ${ }^{19}$ & 2006 & Cohort & 80 & 75 & $2.7(0-6)$ & 75 & 2 & 3 & - \\
\hline Christodoulou et al. ${ }^{20}$ & 2005 & Cohort & 53 & 22 & $<7.0$ & 31 & 20 & 2 & - \\
\hline Christodoulou et al. ${ }^{21}$ & 2006 & Cohort & 69 & - & $<6.5$ & - & - & - & - \\
\hline Benedict $^{15}$ & 2005 & Cohort & 34 & - & $2.5 \pm 2.0$ & 27 & 4 & 3 & - \\
\hline Winkelman et al. ${ }^{2}$ & 2007 & Analysis of confounding factors & - & - & - & - & - & - & - \\
\hline Chiaravalloti, De Luca' & 2008 & Analysis of confounding factors & - & - & - & - & - & - & - \\
\hline Engel et al. ${ }^{4}$ & 2007 & Analysis of tests batteries & - & - & - & - & - & - & - \\
\hline Arnett, Forn ${ }^{7}$ & 2007 & Analysis of tests batteries & - & - & - & - & - & - & - \\
\hline Malik et al. ${ }^{34}$ & 2009 & Analysis of tests batteries & - & - & - & - & - & - & - \\
\hline Benedict, Zivadinov ${ }^{33}$ & 2007 & Analysis of tests batteries & - & - & - & - & - & - & - \\
\hline Beatty $^{32}$ & 1999 & Analysis of tests batteries & - & - & - & - & & - & - \\
\hline Achiron, Barak ${ }^{31}$ & 2006 & Analysis of tests batteries & - & - & - & - & - & - & - \\
\hline Barak, Achiron ${ }^{30}$ & 2002 & Analysis of tests batteries & - & - & - & - & - & - & - \\
\hline Feinstein ${ }^{40}$ & 2004 & Review & - & - & - & - & - & - & - \\
\hline Rogers, Panegyres ${ }^{36}$ & 2007 & Review & - & - & - & - & - & - & - \\
\hline Thomas et al. ${ }^{37}$ & 2006 & Systematic review & - & - & - & - & - & - & - \\
\hline Bagert et al. ${ }^{39}$ & 2002 & General review & & & & & & & \\
\hline Zakzanis $^{38}$ & 2000 & Metanalysis & $1845^{2}$ & 1265 & 4.1 & 636 & - & 351 & - \\
\hline
\end{tabular}

${ }^{1}$ Cases of benign MS; ${ }^{2} 858$ patients with non specified MS clinical form. 
According to Isquierdo ${ }^{35}$, memory definition concerns to the acquisition operations (as a synonym of learning), formation, conservation and evocation of informations. Although there are various systems to classify memory, within this article, we will emphasize those most frequently investigated in MS patients. They are long and short duration working memory, and operational memory.

Working memory, also named immediate memory, is part of short term memory, characterized by a brief and fugacious functioning, that maintains the connection of immediate real facts, not producing files to future use, and lasting few seconds to a maximum of three minutes ${ }^{35}$.

According to storage span, memory can be classified as: [A] short term, which presents a passive storage character; [B] long term, that is the ability to learn new informations and remember those anterior ${ }^{7}$, that is, to store facts for unlimited time, or yet $[\mathrm{C}]$ operational. Operational memory concerns to a system that process and store informations for short periods of time, varying from six to eight hours, with limited storage capacity, but exerting a crucial impact on the execution of complex and routine tasks.

The analyzed studies are in accordance to the existence of memory, processing speed and executive functions deficits of MS patients, but differ on the details concerning to interrelations with depression, fatigue, EDSS, age, disease duration and information processing.

Scherer et al. ${ }^{10}$, on validating Faces Recognition Test, identified that patients with any MS clinical forms related difficulty on verbal and spatial memory. Andrade et al. ${ }^{13}$ referred the same conclusions within a case-control study.

Christodoulou et al..$^{20}$ developed a cohort, with a six months follow-up, involving patients with all MS clinic forms, using or not active drugs, aiming to investigate their perception on memory deficits secondary to this disease. They concluded that this perception exists, but the intensity of deficit could not be evaluated by the patient, possibly because it depends on life habits and daily demands for the use of cognitive functions. Nevertheless, it can also depend on the adaptations the patient makes to compensate these deficits, according to a process the authors named accommodation theory.

Griffiths et al. ${ }^{12}$ included MS patients within a casecontrol study aiming to investigate exclusively global memory deficits. After removing the interference of confounding factors related to age and depression grade, they concluded that there was a impairment on late memory, consisting on a difficulty for retaining old informations (retention of retroactive interferences) after new informations learning (pro-active interferences), resembling to reflect a reduction on mental flexibility that reduces codification efficiency.
Jønsson et al. ${ }^{19}$ included in a cohort MS patients followed by four years, with comparison of groups of all clinical forms and with healthy individuals pared by age, gender and educational level, submitted to four consecutive evaluations, each 14 or 15 months. They proved that six among seven analyzed domains were affected, which included visuospatial memory, processing speed and executive functions. They also demonstrated that memory and processing speed were not the most frequent deficits, and that these could ameliorate by subsequent evaluations. The authors alerted for some confounding factors of memory and processing speed evaluation, among which they suggested a possible patient's blockage during the first tests. However, it seems also plausible to suppose that tests repetition may act as a neuropsychological rehabilitation, since the patients, after these evaluations, spontaneously tried to exercise their cognitive functions.

Huijbregts et al. ${ }^{11}$, based on the results of other studies that suggested memory deficit in MS patients, hypothesized that disease worsening could interfere on that cognitive function, as well as on processing speed. Aiming to prove this assertive, they developed two successive studies. Within the first one, case-control type, they compared MS clinical forms. Proving that the most significant deficit occurred in primary progressive (PP) and secondary progressive (SP) forms, compared to controls and patients with RR form, they developed the second study, as a cohort with a two years follow-up, involving patients with progressive forms. Proving that deficits worsen along time, they attributed this fact to axonal injury, when they excluded EDSS influence.

Schulz et al. ${ }^{5}$, within a case-control study with patients pared to controls by age, gender and educational level, presenting any MS clinical form and EDSS varying from 1 to 7 (median=2), identified that, even patients with RR form, presented impairment on working, visual, late and non verbal memory, although they did not have any intellectual disabilities. These deficits were not associated to depression grade, but worsened in clinical forms with progressive character and with disability aggravation evaluated by EDSS. The authors emphasized that memory and processing speed deficits were present even in early stages of MS, as well as did Amato et al. ${ }^{8}$, Potagas et al. ${ }^{17}$ and Arango-Lasprilla et al. ${ }^{18}$.

These findings were corroborated by Barco et al. ${ }^{6}$, within a study with the same design as that of Schulz et al. ${ }^{5}$, but including exclusively patients with RR clinical form. They proved the existence of verbal and visuospatial memory, as well as processing speed deficits, and emphasized that these deficits were not secondary to the initial acquisition damage, but were due to a reduction on remembering ability. While the reduction on verbal memory compromises working memory, those on spatial mem- 
ory are more generalized and promote difficulties on acquisition and consolidation/recovery, in a slightly symmetric way. On verbal memory, the deficits are present in early phases related to acquisition, and, in spatial memory, acquisition as well as reproduction are involved, driving to high levels of depression.

Potagas et al. ${ }^{17}$ alerted that cognitive prejudices seemed more related to disease worsening than to its duration, since they identified more intense deficits in patients with SP form, when compared to those with PP or RR forms.

Diamond et al. ${ }^{9}$, analyzing the influence of fatigue, depression and processing speed on memory, concluded that depression contributed to slower processing speed, which compromised late memory, possibly by the reduction of brain perfusion in MS, while fatigue promoted an increased effort to retain information.

Concerning to the management of a depressed patient with MS, these findings are relevant because they indicate the need of a precocious intervention as a tentative to reduce the interference of depression on the reduction of memory and quality of life, as well as they are important because of the possibility to stimulate the patient to develop activities that ameliorate their cognitive functions.

Another research profile involves the relation of memory, processing speed and executive functions impairment with alterations identified by image examinations.

Foong et al..$^{25}$ investigated working spatial memory in patients with all MS clinical forms compared to healthy controls, pared by age, to correlate it with lesion volume in frontal lobe, by magnetic resonance with image intensification. They identified that the worse performance of MS patients were not restricted to rate reduction with the increase of test complexity, but involved also a loss of immediate remembering, indicating that there was a real loss, which could not be totally explained by general intellectual decline. By identifying a lack of correlation of total lesion volume in frontal lobe with spatial working memory decline, they judged that this association could be less important than previously admitted.

Randolph et al. ${ }^{24}$ also studied the relation of brain lesion volume (by checking volumetric index in FLAIR images) with processing speed and verbal memory, according to a case-control study, triple blind, involving a radiologist, a neurologist and an evaluator of two tests. They included patients with RR clinical form, EDSS minor than 3 , not using of disease modifying drugs. They concluded that processing speed and verbal memory of MS patients were compromised compared to controls and were associated to lesion volume, independently of EDSS.

Supposing that the reduction of perfusion in white matter with normal appearance and in subcortical gray matter could reflect neuronal and axonal loss, related to cognitive deficits, and, among them, those of memory and processing speed, Inglese et al. ${ }^{26}$ investigated work memory, verbal memory and visuospatial memory, prospectively, in patients with RR and PP forms, and EDSS minor or equal to 7 . By proving the correlation of hypoperfusion in white matter and deep gray matter with memory deficit, they alerted that this damage is related to brain blood flow reduction as a whole, since these cognitive functions depend on a complex diffuse neuronal network, not restricted to cortical areas. It means that deep gray matter can anymore be considered as independent of cortical area and thalamus, with which it maintains afferent and efferent connections.

Mathiesen et al. ${ }^{22}$ identified a significant reduction of memory in patients, when compared to controls, as well as an association of cognitive functions reduction and a $\mathrm{NAA} / \mathrm{Cr}$ rate minor than 1.55 , demonstrating that cognitive decay is associated to metabolic brain modifications.

Morgen et al. ${ }^{28}$ matched 19 MS patients to controls, according to age (22 to 46 years old) and gender, to determine the association between cognitive performance and brain volume, evaluated by magnetic resonance image. They could prove a positive correlation of cognitive loss and cortical atrophy in areas associated to the evaluated domains. They alerted that the lack of a significant association between cognitive deficits, physical disability and lesion volume in white matter evidences the importance to appreciate cortical atrophy as an indication of the necessity to initiate treatment earlier, to delay cognitive deficits.

Mesaros et al. ${ }^{27}$ looked for a major detail on the analysis of the correlation between brain lesions and cognitive deficits. When they analyzed patients with multiple sclerosis considered benign, characterized by EDSS $<3$ after at least 15 years of disease ${ }^{8}$, they proved a positive correlation between decreased cognitive performance and length of corpus callosum lesion. Nevertheless, they identified that patients with these lesions also presented normal neuropsychological tests. They considered that the application of tests could be an strategy to the identification of the truly MS benign form, facilitating to distinguish patients for whom treatment may be unnecessary and postponed for many years.

Dineen et al. ${ }^{16}$ investigated the relations between cognitive loss and damage in white matter tracts, analyzed by magnetic resonance. Besides determining a positive correlation, they identified that the interconnections between the cortical regions or the compensatory processing routes could be involved in cognitive impairment.

Among the studies that integrated the present review, many aspects of memory and processing speed had been evaluated, including visual, spatial, visuospatial, work, mediate/immediate, semantic, retroactive/proactive, and recognition memory, with prejudice in all of them. The 
results suggest also that, although there is retention of initial informations, the neurological alterations determine reduction of late memory due to loss of fixation of these informations.

Based on these studies, it seems plausible to admit that memory and processing speed impairment in MS patients is related to brain metabolism and perfusion alterations, even considering that all authors admitted the need of studies with greater samples, to enhance evidence level.

The difference between Foong et al. ${ }^{25}$ findings compared to those of Randolph et al..$^{24}$ may be related to a more rigorous selection of these researchers, admitting in their study only patients with RR clinical form, while the differences to Mathiesen et al. ${ }^{22}$ and Inglese et al. ${ }^{26}$ studies involved a change on research focus from lesion volume to analysis of brain metabolism and perfusion, respectively.

The comparison of clinical studies findings, with neuropsychological tests application, to image researches shows a relevant difference. There is concordance on memory and processing speed deficits, but it seems plausible to admit that these deficits may derive more to axonal loss than to lesions volume, what could explain the apparent discordance among image studies. Huijbregts et al. ${ }^{11}$ argued that, on PP forms, brain atrophy not always is accompanied by an increase on lesion load in white and gray matter, but, even so, the loss on memory and processing speed are significant.

Memory and processing speed deficits are real, even they may not constitute patients complain, because their perception is hampered by the accommodation process and by a conjoint action of phenomena as depression, fatigue and motor disability, that most commonly are perceived. The studies, analyzed together, authorize to suggest that worsening of these deficits is more related to degenerative process, although the loss begins in the phase with predominance of inflammatory process, as well as maintains an intimate association to brain atrophy than with lesions volume.

To revert the studies' findings into benefit to patients, three conducts of the specialist are necessary. The first is the evaluation of these functions as a routine, and the second consists on the indication of neuropsychological rehabilitation, that can be achieved with processes as simple as to stimulate patients to perform tasks that demand memory and processing speed. The third one is the precocious initiation of drug therapy for MS.

\section{Attention and concentration}

Attention is not a single mental function, but concerns to many processes related to intensity and selectivity. The intensity of attention includes readiness of responses to external demands and the ability to maintain attention during long periods under challenging or unfavorable conditions. Selectivity is integrated by two components: selective attention and divided attention. The selective or focal attention represents the ability to respond to relevant stimuli and ignore those distractive, while divided attention is the ability to distribute limited mental resources to different informations sources ${ }^{29}$.

Differing from what has been verified on memory and processing speed evaluations, those specific to attention and concentration were less frequent and their results, although variable, contained pour details. Only four studies discussed these aspects.

Barco et al. ${ }^{6}$, using digits test, Stroop Test, Paced Auditory Serial Attention Test (PASAT), direct Visual Spam and Viena System, referred that patients with attention and concentration alterations had as characteristics major punctuation on Beck test, were older, had minor instruction level and major EDSS score, compared to patients with preservation of these domains. They considered those intervenient variables as confounders, including the instruction level.

Schulz et al. ${ }^{5}$ applied a battery of specific tests to evaluate attention and reinforced the importance of this evaluation as routine to MS patients, independently of disease duration or lesion extension determined by magnetic resonance image, because they identified mild reduction of attention in RR MS patients, and more intense in progressive forms.

Balsimelli et al. ${ }^{14}$ also utilized a battery of tests directed to attention aspects, with emphasis on frontal lobe, composed by Digit Spam Test, Trail Making Test, Cancelation Test and Stroop Test, but they could not prove deficit on attention in MS patients.

Nebel et al. ${ }^{29}$ applied the Test Battery for Attentional Performance (TAP) version 1.5, associated to selective attention and divided attention tests, aiming to study the relation of loss of brain tissue to attention compromise. Although they could not prove this association, they identified deficits on these attentions.

It is important to emphasize that the attention deficits seem to be present. Nevertheless those on concentration are less investigated than the other cognitive domains. This precludes any affirmation on concentration deficits.

\section{Visuoconstructive and visuospatial abilities}

Visuoperceptive functions (visuospatial and visuoconstructive) include not only the recognition of visual stimulus, but also the ability to detect with details the stimulus characteristics ${ }^{1}$.

As pointed out by Winkelman et al. ${ }^{2}$, visuoconstructive and visuospatial abilities are still less investigated in MS patients. In this review, among 15 studies that utilized 
tests to evaluate these functions, only three informed results as mean and standard deviation scores.

Barco et al. ${ }^{6}$ explain this absence due to the supposition that the deficits in visuoconstructive and visuospatial abilities were related to peripheral visual problems. To exclude the possible visual bias, these authors performed a study including patients with normal visual function, what allowed them to state that the deficits on visuoconstructive and visuoperceptive abilities could not be associated to primary visual alterations. Besides, the patients presented normal performance on line orientation test, proving to have preserved sensorial visual functions.

Barco et al. ${ }^{6}$ concluded that visuospatial and visuoconstructive alterations of MS patients, identified by a minor score on faces recognition test and cubes construction test, compared to controls, were related to visuoperceptive damage, that could not be attributed to motor slowness, since patients and controls did not differ on time to perform the tests.

Schulz et al. ${ }^{5}$ used Rey-Osterrrieth complex figure test and identified that MS patients had scores ( $35 \pm 7.2$ points) significantly minor than controls ( $36 \pm 0.9$ points).

Jønsson et al. ${ }^{19}$, including patients with minor than one year time of disease, verified that $34.7 \%$ presented deficit of visual organization, and $17.9 \%$, of visuospatial memory. After a four years of follow up, the authors verified improvement on visuospatial memory, attributed to tests repetition along the research, and a significant deterioration on visual organization.

Within this analysis, one can infer that MS patients have damage on visuoperceptive functions, but data are still insufficient to offer evidence level.

\section{Information processing}

Information processing refers to ability to maintain and manipulate information in brain during a short time period and to velocity to process this information ${ }^{1}$.

Deficits on information processing are considered by Chiaravalloti and De Luca ${ }^{1}$ as the most frequent amongst MS patients, and tests can be used as long term predictors of cognitive decline. The authors stand out that those damages on information processing can be hidden as memory or attention alterations, demanding to be evaluated by specific tests.

The alert of Chiaravalloti and De Luca ${ }^{1}$ seems adequated when we identify, amongst the articles included in this review, that this domain has not been evaluated by specific tests and, when the domain is discussed, it has been included to processing speed or to memory.

\section{Learning, orientation and verbal fluency}

Learning, a cognitive function that consists on retention of knowledge, consequent to study and observations or experiences successively repeated, orientation and verbal fluency have been less investigated in MS patients, although the authors refer the use of tests able to evaluate these functions. A probable hypothesis to explain the lack of studies with this focus may be the close association between memory and learning, complementary processes, but distinct.

Due to this reason, there are few data on learning, orientation and verbal fluency damages in MS patients. According to Barco et $\mathrm{al}^{6}{ }^{6}$, these patients present an acquisition deficit, requiring more time to learn. On verbal fluency, Foong et al. ${ }^{25}$ only referred that MS patients were able to verbalize a minor number of words on words beginning with $\mathrm{S}$ test and animal category test, indicating a worse performance.

These commented results, undoubtedly, prove that MS patients have cognitive deficits and, although all researches emphasize major frequency of compromises on memory, processing speed, cognitive function, attention, and concentration, it is quite impossible to affirm that deficits of other functions are more rare, because they are less investigated. Beyond that, two other factors may compromise this conclusion. One of them is related to the presence of confounding factors, and the other, to the hudge variety of tests and batteries used.

\section{Confounding factors - Age and gender}

We could not find any reference on the studies included in this review to these two variables on cognitive functions. Nevertheless, the majority of researches case-control type adopted age and gender matching between cases and controls, supporting the supposition that these differences may act as confounding factors.

Undoubtedly, the aging process compromises cognitive functions, while hormonal modifications, characteristic of menopause also do. Due to the fact that MS is more prevalent in female gender, these reasons might guide researchers to exclude the interference of these variables on the studies.

\section{Instruction levels}

We identified that many researchers of this review also matched cases and controls according to instruction levels. Although, only Barco et al. ${ }^{6}$ included the variable in the analysis of cognitive functions, demonstrating that patients with minor deficits had major instruction level. The authors considered that instruction level increase the cognitive background, slowing attention and concentration decline during MS evolution.

\section{Motor disability}

It is interesting to point out the frequency of EDSS inclusion as variable in the studies of cognitive evaluation, although many of them had not identified a corre- 
lation of cognitive deficits and EDSS. This fact seems to base the supposition that this inclusion may be the historical reflex of the EDSS as predictor of disease evolution, as well as the recent interest on the evaluation of cognitive functions.

An example of this affirmation is the study of Inglese et $\mathrm{al}^{26}{ }^{26}$, using MRI with perfusion. By identifying that the hypoperfusion of white and gray matter maintains correlation with cognitive loss more than with EDSS, they emphasized that this scale aims primordially to evaluate motor disability and has low sensibility to cognitive deficits.

The study of cognitive functions puts forward a large amount of questions on the interactions of brain areas and functions of deep gray matter, as well as has elicited the curiosity of researchers on the involvement of basal ganglia and thalamus on cognitive functions ${ }^{26}$.

\section{Oral motor function disability}

Cognitive functions, whose tests require oral expression, as verbal fluency, learning and memory, may be disturbed due to the reduction of oral motor function, but this disadvantage, maybe being minimal, has not been included in the studies.

Probably to reduce the action of this confounding factor, researchers and clinic physicians elect tests with oral responses, which may arise the false impression of a speech deficit that, in fact, derives from reduction of an oral motor function. This fact may contribute to a diagnostic error of cognitive functions deficits ${ }^{1}$.

\section{Depression}

Depression in multiple sclerosis cannot be considered only as a symptom or a sign, because it elicit and is elicited by a complex series of events that interact, and difficult or even impede the determination of causal relations.

The researches have demonstrated a relation between emotional symptoms and cognitive functions in many patients with neurologic diseases, as well as in MS. Nearly $50 \%$ to $60 \%$ of MS patients have depression in any moment of disease evolution and the depression itself can compromise considerably cognitive and non cognitive functions, but this interaction is not well elucidated ${ }^{2}$. It seems to be related to therapeutic effect and to fatigue ${ }^{40}$.

Besides the relation between depression and cognitive deficit, it must be emphasized that the depression in MS patients is more intense than in other neurologic diseases, as well as, compared to general population, it is three to ten times more frequent and represents a risk seven times major to suicide. This confirms the need to alert neurologists to consider this complex network of events ${ }^{40}$.

While the basic phenomenology of depression in MS superposes to the finding of primary depression, certain symptoms are more typical and other occasional. So irri- tability, discouragement, and feeling of frustration more frequently are associated to humor alterations in MS than feeling of guilty and low self-steam. Loss of appetite, insomnia, memory and concentration difficulties can be related either to depression or to $\mathrm{MS}^{40}$.

Image studies allowed the demonstration that depression is more frequent in patients: with spinal cord lesions than only with brain lesions; with severe atrophies in parietal and frontal white matter, independently of neurological disability, due to disconnection of limbic functions, and with major number of lesions in temporal region ${ }^{1}$.

\section{Fatigue}

Fatigue, referred by $90 \%$ of MS patients, has been associated with cognitive deficit. It is admitted that cognitive decline may cause increase of fatigue derived from the need to more effort (that may provoke exhaustion), but the increase of fatigue itself does not result on reduction of performance on cognitive functions ${ }^{2}$.

Nevertheless, Chiaravalloti and De Luca ${ }^{1}$ considered that fatigue, in these patients, must be classified in physical and cognitive, being the last one of difficult evaluation, acting as a confounding factor in work memory, processing speed or other activities that require maintenance of mental effort for a while.

By this reason, it has recommended that long lasting neuropsychological tests or those with time evaluation must be avoided, due to the action of fatigue as confounding factor.

\section{Use of disease modifying drugs}

Therapy with multiple sclerosis modifying drugs undoubtedly changes the disease course, but the evaluation of cognitive functions routinely is not considered as interest variable, and, when included in studies, it occupies a second plan. So, the impact of treatment on cognitive symptoms is not completely established ${ }^{36}$, impeding the classification of disease modifying drugs as confounding factors in researches directed to cognitive impairment in MS.

This statement is based on the establishment of inclusion and exclusion criteria of studies included in this review. While Randolph et al. ${ }^{24}$ and Barco et al. ${ }^{6}$ considered treatment with disease modifying drugs within exclusion criteria, demonstrating the settlement of the possible alteration on cognitive evaluation findings, secondary to the action of these drugs, Inglese et al. ${ }^{26}$, Thomas et al. ${ }^{37}$, Scherer et al. ${ }^{10}$ and Chistodoulou et al. ${ }^{21}$ analyzed these deficits in patients using these medications. One must reinforce that the objective of these four researches was not to evaluate therapeutical effect of these drugs on cognitive impairment.

According to methodological point of view, it seems coherent to admit the use of disease modifying drugs as 
confounding factor in researches that aim to evaluate cognitive deficits, because the evidence level on the relation between use of disease modifying drugs and cognitive functions is still very low. Researches are scarce, use small samples and, as will be discussed bellow, the process of evaluation is still not consensual ${ }^{1}$.

\section{Techniques and batteries for} cognitive functions evaluation

The study of MS patients cognition must not be considered only for diagnose, but integrate planning of a rehabilitation program, mainly considering that the disease evolution may, actually, be delayed, allowing to patient a longer period with quality of life $\mathrm{e}^{30,32}$.

One can infer, from the analysis of the studies included in this review, that it is not possible yet to consider tests battery for cognitive evaluation. In 26 articles, there was reference of 23 batteries and 74 distinct tests included to evaluated nine cognitive domains. Ordering the most referred tests, according to frequency, the list is: Symbol digit modality test, Rey-Osterreith complex figure test or Rey visual design learning test, Paced Auditory Serial Attention Test, California verbal learning test, Tower of London and 7/24 spatial recall test.

In 2001, the Consortium of MS Centers, localized in Unit States, Canada, United Kingdom and Australia, jointed a group of neuropsychologists and psychologists with experience on MS patients cognitive evaluation, to determine a minimal battery that could be applied within no more than 90 minutes. They established that five neurocognitive domains (processing speed and work memory, executive functions, learning and memory, language and spatial processing) ought to be investigated by seven tests (Symbol digit modality test, PASAT, California verbal learning test, Controlled Oral Word Association Test, The Judgment of Line Orientation Test, Brief Visual Spatial Memory Test, Dellis-Kaplan Executive Function System Sorting Test). This battery was named as Minimal Assessment of Cognitive Function in Multiple Sclerosis ${ }^{31}$.

It must be emphasized that, even with this recommendation, the studies performed from 2001 to 2009 did not use this battery, except three of them. Arnett and Forn', in 2007, did not evaluate cognitive functions, but corroborated the Consortium's recommendation. Benedict ${ }^{15}$ analyzed the effects of neuropsychological evaluation repetition with MACFIMS battery and Benedict et al. ${ }^{41}$ standardized this battery specifically to Spanish MS patients.

If we achieve the diversity of domains and tests analyzed, independently of authors' nationality, none of them evaluated all domains, although the analysis of articles let identify that all domains were impaired, with distinct intensity. Within this point of view, we could not identify the main reasoning line covered by the authors on the definition of their tests batteries.
The evaluations of memory, executive function, processing speed, visuospatial ability, learning, attention and verbal fluency were predominant, while domains as concentration, information processing, abstract reasoning, visuoconstructive ability and orientation were restricted to some studies. It means that, on epidemiological point of view, the dispersion of informations does not permit an evidence level to justify the implementation of routine cognitive evaluation.

Benedict and Zivadinov ${ }^{33}$ pointed out other reasons to this non implementation, even considering the increasing international interest on this subject. First of all, cognitive evaluation does not integrate MS diagnostic criteria, and, secondly, physicians have no experience on performing this evaluation. On the other hand, tests application consumes a great amount of time during consultation and are expensive.

There is no consensus concerning to domains, as has been verified on the non adoption of tests battery recommended by MS Consortium. In 2009, Malik et al. ${ }^{34}$, analyzing neuropsychological evaluation, identified nine cognitive domains (intellectual function, language processing, visuospatial processing, attention and concentration, verbal learning and memory, visual learning and memory, executive function, processing speed, sensorial perceptual functions) against five of Consortium.

This emphasizes that, within the analyzed studies, the evaluations did not refer to domains, but to some aspects, so they were punctual.

\section{Final considerations}

The analysis of the articles within this review permitted more than the simple identification of MS patients cognitive impairment, specially on memory, processing speed, executive function, attention and concentration domains, but let two primordial reflection points. The first one is to identify the existence of a tendency to include cognitive evaluation of MS patients within diagnostic routine, since these deficits may be present in early phases of disease.

The second reflexion consists on considering that the search for the better way to a reliable diagnose seems to delay an evidence level. The MS Consortium recommendation to use an unique battery may be the first step to solve this crucial problem, before an standardization and recognition of a first cognitive profile, researches with wide and diverse evaluation tests will not represent an effective gain to patients.

\section{REFERENCES}

1. Chiaravalloti ND, DeLuca J. Cognitive impairment in multiple sclerosis. Lancet Neurol 2008;7:1139-1151.

2. Winkelmann A, Engel C, Apel C, Zettl UK. Cognitive impairment in Multiple Sclerosis. J Neurol 2007;254(Suppl 2):S35-S42. 
3. Amato MP, Portaccio E, Zipoli V. Are the protective treatments for cognitive decline in MS? J Intern Neurol Scien 2006;245:183-186.

4. Engel C, Greim B, Zettl UK. Diagnostics of cognitive dysfunctions in multiple sclerosis. J Neurol 2007;254(Suppl 2):S30-S34

5. Schulz D, Kopp B, Kunkel A, Faiss JH. Cognition in the stage multiple sclerosis. J Neurol 2006;253:1002-1010.

6. Barco AN, López MPS, Ribal JB, Pérez TO, Pérez MÁH. Alteraciones cognitivas en etapas iniciales de la esclerosis múltiple y su relación con el estado de ánimo, variables demográficas y clínicas. Psicothema 2008;20:583-588.

7. Arnett P, Forn C. Evaluación neuropsicológica en la esclerosis múltiple. Rev Neurol 2007:44:166-172

8. Amato MP, Portaccio E, Zipoli V. Are the protective treatments for cognitive decline in MS? J Intern Neurol Sci 2006;245:183-186.

9. Diamond BJ, Johnson SK, Kaufman M, Graves L. Relationships between information processing, depression, fatigue and cognition in multiple sclerosis. Arch Clin Neuropsychol 2008;23:189-199.

10. Scherer P, Penner IK, Rohr A, et al. The faces symbol test, a newly developed screening instrument to assess cognitive decline related to multiple sclerosis: first results of the Berlin Multi-Centre FST Validation Study. Multiple Sclerosis 2007;13:402-411.

11. Huijbregts SCJ, Kalkers NF, Sonneville LMJ, Groot V, Polman CH. Cognitive impairment and decline in different MS subtypes. J Neurol Sci 2006:245:187-194.

12. Griffiths SY, Yamamoto A, Boudreau VG, Ross LK, Kozora E, Thornton AE. Memory interference in multiple sclerosis. JINS 2005;11:737-746.

13. Andrade VM, Bueno OFA, Oliveira MGM, Oliveira ASB, Oliveira EML, Miranda MC. Cognitive profile of patients with relapsing remitting multiple sclerosis. Arq Neuropsiquiatr 1999;57:775-783.

14. Balsimelli S, Mendes MF, Bertolucci PHF, Tilbery CP. Attention impairment associated with relapsing-remitting multiple sclerosis patients with mild incapacity. Arq Neuropsiquiatr 2007;65:262-267.

15. Benedict RHB. Effects of using same - versus alternate-form memory tests during short-interval repeated assessments in multiple sclerosis. J Intern Neuropsychol Soc 2005;11:727-736.

16. Dineen RA, Vilisaar J, Hlinka J, et al. Disconnection as a mechanism for cognitive dysfunction in multiple sclerosis. Brain 2009;132:239-249.

17. Potagas C, Giogkaraki E, Koutsis G, et al. Cognitive impairment in different MS subtypes and clinically isolated syndromes. J Neurol Sci 2008;267:100-106.

18. Arango-Lasprilla JC, de Luca J, Chiaravalloti N. El perfil neuropsicológico en la esclerosis múltiple. Psicothema 2007;19:1-6.

19. Jønsson A, Andresen J, Storr L, Tscherning T, Sørensen PS, Ravnborg M. Cognitive impairment in newly diagnosed multiple sclerosis patients: A 4-year follow-up study. J Neurol Sci 2006;245:77-85.

20. Christodoulou C, Melville P, Scherl WF, et al. Perceived cognitive dysfunction and observed neuropsychological performance: longitudinal relation in persons with multiple sclerosis. J Intern Neuropsychol Soc 2005;11:614-619.

21. Christodoulou C, Melville P, Scherl WF, MacAllister WS, Elkins LE, Krupp LB. Effects of donepezil on memory and cognition in multiple sclerosis. J Neurol Sci 2006;245:127-136.
22. Mathiesen HK, Jønsson A, Tscherning T, et al. Correlation of global N-Acetyl aspartate with cognitive impairment in multiple sclerosis. Arch Neurol 2006; 63:533-536.

23. Penner IK, Kappos L, Rausch M, Opwis K, Radü EW. Therapy-induced plasticity of cognitive functions in MS patients: insights from fMRI. J Physiol 2006;99: 455-462.

24. Randolph JJ, Wishart HA, Saykin AJ, et al. FLAIR lesion in multiple sclerosis: relation to processing speed and verbal memory. J Intern Neuropsychol Soc 2005; 11:205-209.

25. Foong J, Rozewicz L, Quaghebeur G, et al. Executive function in multiple sclerosis the role of frontal lobe pathology. Brain 1997;120:15-26.

26. Inglese $M$, Adhya $S$, Johnson $G$, et al. Perfusion magnetic resonance imaging correlates of neuropsychological impairment in multiple sclerosis. J Cereb Blood Flow Metab 2008;28;164-171.

27. Mesaros S, Rocca MA, Riccitelli G, et al. Corpus callosum damage and cognitive dysfunction in begin MS. Human Brain Mapping 2009;30:2656-2666.

28. Morgen K, Sammer G, Courtney SM, et al. Evidence for a direct association between cortical atrophy and cognitive impairment in relapsing-remitting MS. Neurolmage 2006;30:891-898.

29. Nebel K, Wiese H, Seyfarth J, et al. Activity of attention related structures in multiple sclerosis. Brain Res 2007;1151:150-160.

30. Barak Y, Achiron A. Effect of Interferon-beta-1b on cognitive functions in multiple sclerosis. Eur Neurol 2002;47:11-14.

31. Achiron A, Barak Y. Cognitive changes in early MS: a call for a common framework. J Neurol Sci 2006;245:47-51.

32. Beatty WW. Cognitive dysfunction in multiple sclerosis: natural history and impact on productive living. Ital J Neurol Scien 1998;19(Suppl): S381- S387.

33. Benedict RHB, Zivadinov R. Reliability and validity of neuropsychological screening and assessment strategies in MS. J Neurol 2007;254(Suppl 2): S22-S25

34. Malik AB, Turner ME, Sadler C. Neuropsychological evaluation. eMedicine 2009. Disponível em: http://www.emedicine.medscape.com/article/317596print. Acesso em: 24/09/2009.

35. Izquierdo I. Memória. Porto Alegre: Artmed 2002

36. Rogers JM, Panegyres PK. Cognitive impairment in multiple sclerosis: evidence-based analysis and recommendations. J Clin Neurosci 2007;14: 919-927.

37. Thomas PW, Thomas S, Hillier C, Galvin K, Baker R. Psychological interventions for multiple sclerosis. Oxford: Update Software. The Cochrane Library 2006.

38. Zakzanis K. Distinct neurocognitive profiles in multiple sclerosis subtypes. Arch Clin Neuropsychol 2000;15:115-136.

39. Bagert B, Camplair $P$, Bourdette D. Cognitive dysfunction in multiple sclerosis. CNS Drugs 2002;16:445-455

40. Feinstein A. The neuropsychiatry of multiple sclerosis. Can J Psychiatry 2004; 49:157-163.

41. Benedict RHB, Cookfair D, Gavett R, et al. Validity of the minimal assessment of cognitive function in multiple sclerosis. J Intern Neuropsychol Soc 2006; 12:549-558. 